\title{
Seismic Performance of High-Strength Self-Compacting Concrete in Reinforced Concrete Beam-Column Joints
}

\author{
M. Soleymani Ashtiani, R. P. Dhakal \& A. N. Scott \\ Department of Civil and Natural Resources Engineering, University of Canterbury, \\ Christchurch, New Zealand
}

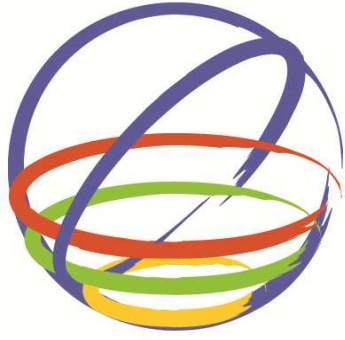

15 WCEE

\begin{abstract}
SUMMARY:
Beam-column joints of reinforced concrete building frames play an important role under seismic excitations. These are one of the most congested areas in reinforced concrete framed structures; placement of concrete and proper compaction in such areas are hence substantially challenging. This offers a unique area of application for self-compacting concrete which can flow through every corner of extensively reinforced area without any vibration. Therefore if implementing self-compacting concrete in beam-column joints does not compromise seismic performance of the frame, it can be used instead of conventional concrete.
\end{abstract}

This paper focuses on implementation of high-strength self-compacting concrete in beam-column joints and assessment of its seismic behaviour under reversed cyclic loading. Three interior beam-column subassemblies chosen to vary in concrete type and compressive strength are designed as per the New Zealand Standard NZ3101:2006. The specimens are instrumented to measure the load, displacement/drift, ductility, joint shear deformations, and elongation of the plastic hinge zone. The cracking pattern at different load levels and the mode of failure are also recorded and compared among different specimens.

Keywords: Beam-Column Joints, High-Strength, Self-Compacting Concrete, Seismic Performance

\section{INTRODUCTION}

Due to its special fresh and mechanical properties, Self-compacting concrete (SCC) has been regarded as one of the most important advances in concrete technology after its advent more than two decades ago. It has a unique ability to flow into a uniform level under the influence of gravity with the ability to compact by means of its self-weight without any external or internal vibration. Based on its exceptional flowing properties, SCC is able to be implemented in complex formworks even in highly congested reinforced concrete (RC) members. Therefore, the interest in utilizing SCC in members of concrete framed structures has increased manifold over the recent years.

The intersection of beams and columns represents one of the most congested parts of RC framed structures. Placing and consolidating concrete in such areas has often imposed difficulties which results in imperfect compaction and/or segregation of concrete. This entails other side effects such as deteriorated bond properties which later on associates with provision of more column depth than otherwise required in many of the RC standards. Considering the advantages of SCC (noise reduction, reduced labour force, higher material quality and better surface finish) over conventionally vibrated concrete (CVC), if the seismic performance is not compromised, the application of SCC in beamcolumn joints $(\mathrm{BCJ})$ can be beneficial.

Literature shows extensive investigations on fresh and mechanical properties (compressive, splitting tensile, and flexural strengths as well as modulus of elasticity, shrinkage and bond strength) of SCC including their comparison with that of CVC (Soleymani Ashtiani et al., 2011, Soleymani Ashtiani et al., 2010, Desnerck et al., 2010, Valcuende et al., 2009, De Almeida Filho et al., 2008, Domone, 2006, 
Persson, 2001). In addition, researchers have been working on the structural performance in RC members cast with SCC under monotonic loads in the past few years (Hassan et al., 2008, Lachemi et al., 2005, Sonebi et al., 2003). Nevertheless, to the best of the authors' knowledge only a few researchers have looked into the seismic behaviour of reinforced concrete beam-column joints cast with SCC (Said et al., 2007).

Following the Canadian and American standards, Said et al (2007) fabricated a SCC exterior beamcolumn joint with 28-day compressive strength of $50 \mathrm{MPa}$ and investigated its performance under reversed cyclic loading. They also compared the behaviour of the SCC joint with that of a CVC benchmark specimen of the same concrete compressive strength range. They reported that the SCC specimen showed comparable cracking behaviour, load and displacement capacities and mode of failure to that of $\mathrm{CVC}$ up to $4.5 \%$ drift after which a faster reduction in load carrying capacity for SCC was observed. They attributed this to the lower coarse aggregate content in SCC which results in lesser friction due to aggregate interlocking; thus smaller contribution in the total shear resistance mechanism especially at the higher drifts. This was also reported to have resulted in a lower concrete contribution towards shear resistance in the beam for SCC specimen compared to that of CVC.

In the present study a high-strength self-compacting concrete (HSSCC) mix was utilized to fabricate and assess the performance of an interior RC beam-column joint under reversed cyclic loading. Benchmark specimens of conventionally vibrated high-strength concrete (CVHSC) and normal strength CVC were also tested for comparison purposes. All specimens were instrumented with linear variable displacement transducers (LVDT) on the joint and beam regions, strain gauges on both longitudinal and transverse reinforcements at different locations, load-cells at the lateral loading point and beam tips and pressure transducer at the hydraulic jack pipeline to measure the column axial load. Recorded data was used to calculate the load vs. displacement, ductility, beam elongation, stiffness degradation, energy dissipation, deformation of the components and the joint, and contribution of steel and concrete in the joint shear stress.

\section{EXPERIMENTAL INVESTIGATIONS}

\subsection{Beam-column joint, test setup and load protocol details}

In the present investigation, locally available materials in Christchurch, New Zealand were used in order to design different concrete mixes; namely a high-strength self-compacting concrete (HSSCC), a conventionally vibrated high-strength concrete (CVHSC) and a normal-strength conventionally vibrated concrete (CVC) mix. (Table 2.1.1) Details of physical properties of the cement, fly ash, and aggregates as well as the mixing method and procedure are described in a previous study (Soleymani Ashtiani et al., 2010).

Table 2.1.1. Different concrete mix proportions and properties

\begin{tabular}{|l|l|l|l|}
\hline & HSSCC & CVHSC & CVC \\
\hline Coarse aggregate $\left(\mathrm{kg} / \mathrm{m}^{3}\right)$ & 880 & 1145 & 1045 \\
\hline Fine aggregate $\left(\mathrm{kg} / \mathrm{m}^{3}\right)$ & 870 & 695 & 930 \\
\hline Cement $\left(\mathrm{kg} / \mathrm{m}^{3}\right)$ & 385 & 385 & 265 \\
\hline Fly ash $\left(\mathrm{kg} / \mathrm{m}^{3}\right)$ & 165 & 165 & - \\
\hline Water $\left(\mathrm{kg} / \mathrm{m}^{3}\right)$ & 165 & 148.5 & 158 \\
\hline Super-plasticizer $\left(\mathrm{kg} / \mathrm{m}^{3}\right)$ & 3.58 & 1.93 & 0.79 \\
\hline w/b ratio $($ designed $)$ & 0.30 & 0.27 & 0.60 \\
\hline w/b ratio $($ actual $)$ & 0.28 & 0.29 & 0.61 \\
\hline Slump $(\mathrm{mm})$ & 600 & 150 & 80 \\
\hline Compressive strength $(\mathrm{MPa})$ & 124.3 & 82.5 & 48.4 \\
\hline Splitting tensile strength $(\mathrm{MPa})$ & 7.0 & 6.5 & 4.7 \\
\hline
\end{tabular}

Three standard beam-column joints, namely BCJ1 (HSSCC), BCJ5 (CVHSC) and BCJ6 (CVC), were 
designed following the current New Zealand Standard (NZS3101, 2006) requirements to achieve a strong-column-weak-beam hierarchy where the final expected mode of failure was hinging of the beam at the column face. Based on capacity design principals, column was designed to remain elastic throughout the test; this was ensured by keeping the ratio of the factored yield moment of the column $\left(\varphi \mathrm{M}_{\mathrm{y}}\right)$ to the over-strength moment of the beam $\left(\mathrm{M}_{\mathrm{o}, \mathrm{b}}\right)$ well above 1.0 for all specimens. The detailing of the reinforcement was identical in all three specimens (Fig. 2.1.1). Ratios of the longitudinal reinforcement in the beam (tension side) and column were 0.011 and 0.025 , respectively which were within the limits specified by the New Zealand Standard (NZS3101, 2006).

In order to measure the local strains, strain gauges with $3 \mathrm{~mm}$ gauge length were installed on the top and bottom longitudinal beam bars as well as the shear reinforcement in the joint, beam and column (only the two stirrups adjacent to the joint). In addition, the beam plastic-hinge zone, beam-column interface and the joint panel were instrumented with LVDTs (installed on the surface) in order to measure the average strains, beam flexural and shear deformations, plastic-hinge zone elongation and joint shear deformations. It should be noted that as the column was designed to remain elastic, monitoring its deformations were not necessary; thus it was not instrumented with LVDTs or strain gauges (Fig. 2.1.1).

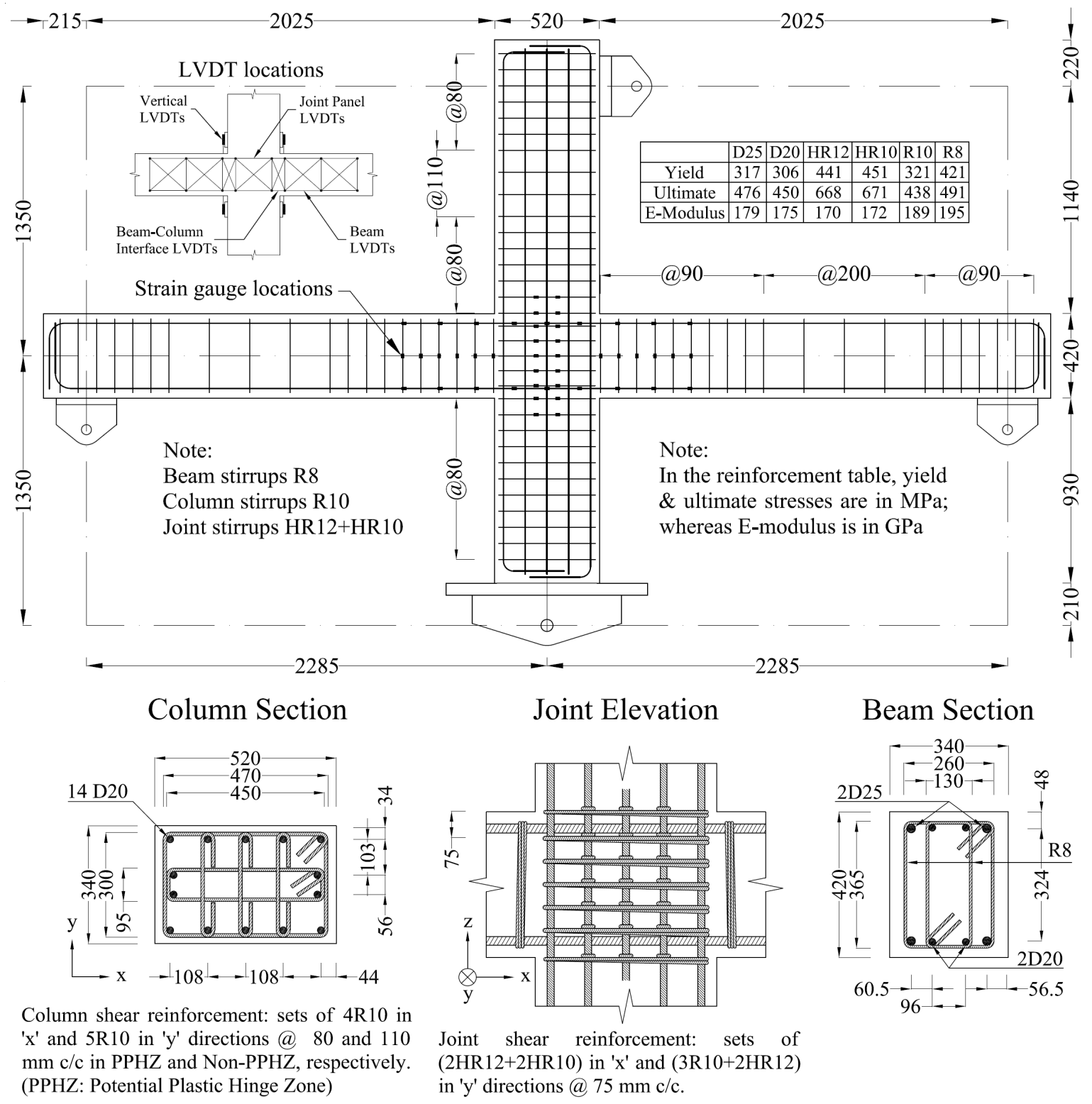

Figure 2.1.1. Details of the beam-column subassemblies and instrumentations (dimensions are in ' $\mathrm{mm}$ ') 
The lateral load was applied to the top of the column through a $400 \mathrm{kN}$ capacity hydraulic actuator (ram) and measured using a load-cell. The ram was supported on the west by a strong reaction frame designed to take twice the actuator maximum capacity. The displacement was fed to the hydraulic actuator through a portable computer and associated controller. This was measured with a rotary potentiometer (located at the level of the actuator) which was connected to an independent frame to make sure that the possible slack in the setup will not affect the loading history. The designed axial load was applied through a $2500 \mathrm{kN}$ capacity hydraulic jack and transferred to the column through the top and bottom plates and Macalloy bars. The bottom of the column and beam-ends were fixed to the strong floor using a pin and two roller supports, respectively. The generated loads at the end of the beams were measured using two load-cells. Fig. 2.1.2 shows a schematic view of the setup used to test the beam-column subassemblies as well as an actual picture of a typical specimen before test.

A quasi-static displacement-controlled loading regime (Fig. 2.1.2.b) was adopted following the ACI guidelines for moment resisting frames (ACI374.1-05, 2005). The positive (+) and negative (-) drift directions were chosen based on the sign convention given in Fig. 2.1.2.a. Up to the $0.5 \%$ drift cycles, displacement increments of $0.5 \mathrm{~mm}$ were used in each loading step; however $1 \mathrm{~mm}$ increments were used for the rest of the cycles. Each displacement cycle was repeated 3 times and starting after the $0.5 \%$ drift cycle, a small cycle (1/3 magnitude of the preceding one) followed each cycle set.
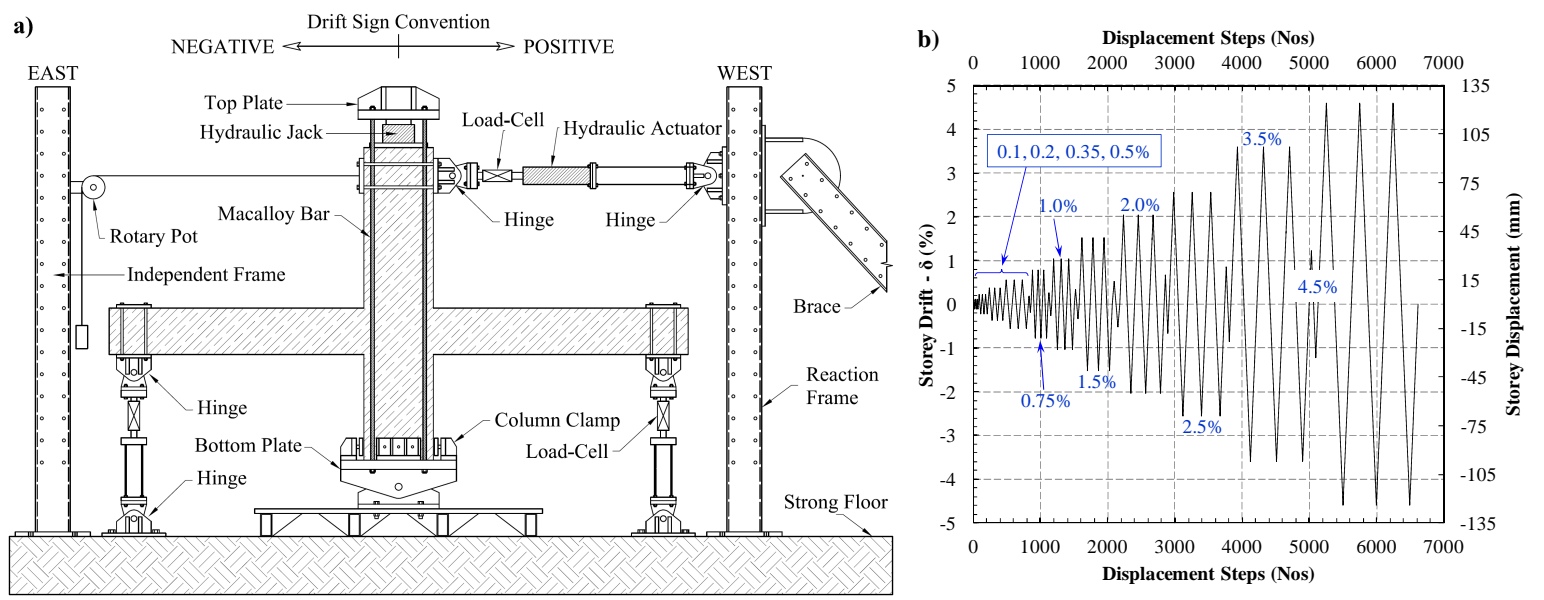

Figure 2.1.2. a) Schematic view of the test setup and b) Displacement regime

\subsection{Testing procedure and experimental results}

The axial load was monitored and maintained throughout the test (using a pressure transducer) such that $\mathrm{N}^{*} /\left(\mathrm{A}_{\mathrm{g}} \mathrm{f}_{\mathrm{c}} \mathrm{f}_{\mathrm{c}}\right)$ remained almost the same for all specimens $(0.07,0.10 \& 0.08$ for BCJ1, BCJ5 and BCJ6, respectively); where ' $\mathrm{N}^{*}$ ' is the design axial load $(\mathrm{N})$, ' $\mathrm{A}_{\mathrm{g}}$ ' is the gross sectional area of the column $\left(\mathrm{mm}^{2}\right)$ and ' $\mathrm{f}_{\mathrm{c}}$ ' ' is the concrete compressive strength on the day of test (MPa). A data logger and associated computer were used to automatically collect the readings of the rotary pot, load-cells, LVDTs and strain gauges at each displacement increment throughout the test. The test was paused at both ' + ' and '-' peaks of the $3^{\text {rd }}$ cycle of each drift set. At each pause, cracks were marked and labelled with the drift, crack-widths were measured (using a hand microscope of $0.01 \mathrm{~mm}$ accuracy) and pictures were taken of the overall specimen and different damaged parts. In order to follow the crack patterns more efficiently, two grids of size $65 \mathrm{~mm}$ and $100 \mathrm{~mm}$ were drawn on the joint and beam surfaces, respectively. A test report was completed at every pause in order to associate the observations and manually collected data. Fig. 2.2.1.a-c shows the storey shear versus drift response for the three specimens tested.

The yield and test-end points (including displacement ' $\Delta$ ', drift ' $\delta$ ', and storey shear) are annotated based on the test observations and the change in stiffness. The horizontal solid lines in Fig 2.2.1 (just above the yield points) show the predicted shear strength of the specimens calculated based on the 
factored nominal moment capacity of the beam $\left(\varphi \mathrm{M}_{\mathrm{n}}\right)$. Based on the ACI recommendations (ACI374.1-05, 2005) the limiting drift value for the RC moment resisting frames is $3.5 \%$. However the adopted displacement protocol and test setup in this study allowed for a maximum drift of $4.5 \%$ which was applied to all specimens. Note that none of the specimens had failed when the test was terminated at the maximum drift of $4.5 \%$.

Fig. 2.2.2 shows the physical condition of the joint in different specimens at positive drift ratios of $2.5 \%$ and $4.5 \%$. It is clear from the pictures that the BCJ6 (CVC) had considerably more cracks in the joint area compared to that of BCJ1 and BCJ5; however the final mode of failure in all three specimens was the hinging of the beam. Please note that in $\mathrm{BCJ} 1$, the broken concrete pieces were forcibly removed from the top and bottom of the specimen; that's why the $4.5 \%$ drift picture of $\mathrm{BCJ} 1$ looks more deteriorated than BCJ5 and BCJ6.
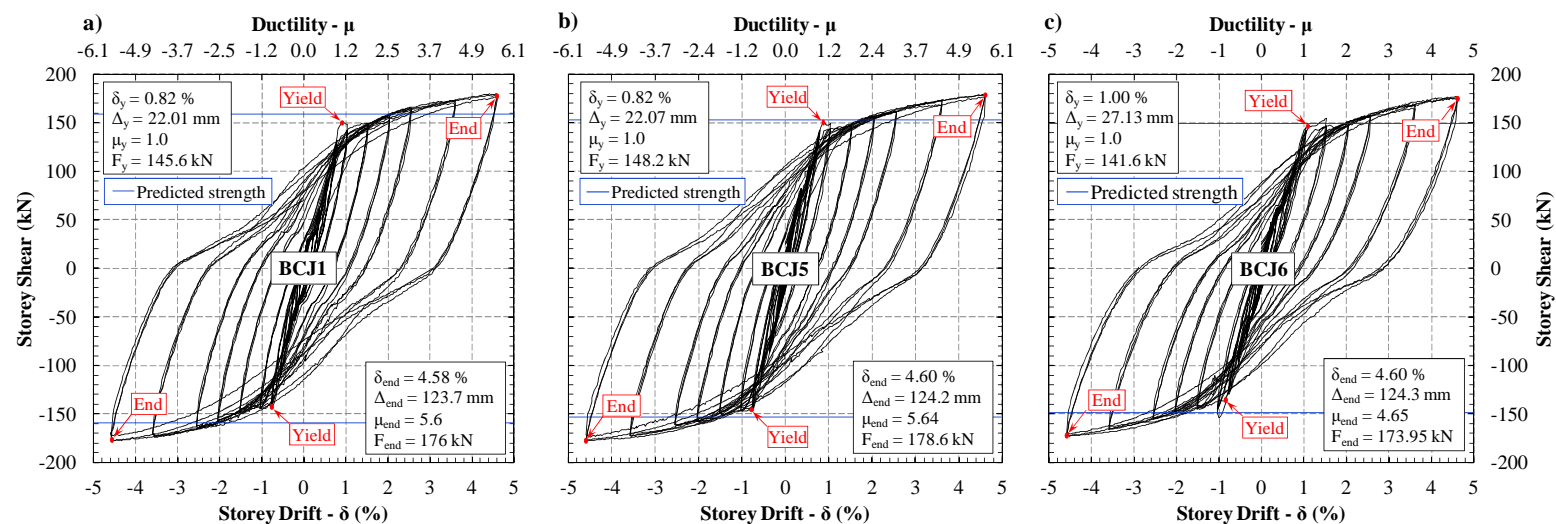

Figure 2.2.1. Experimental Load vs. drift graphs for specimens
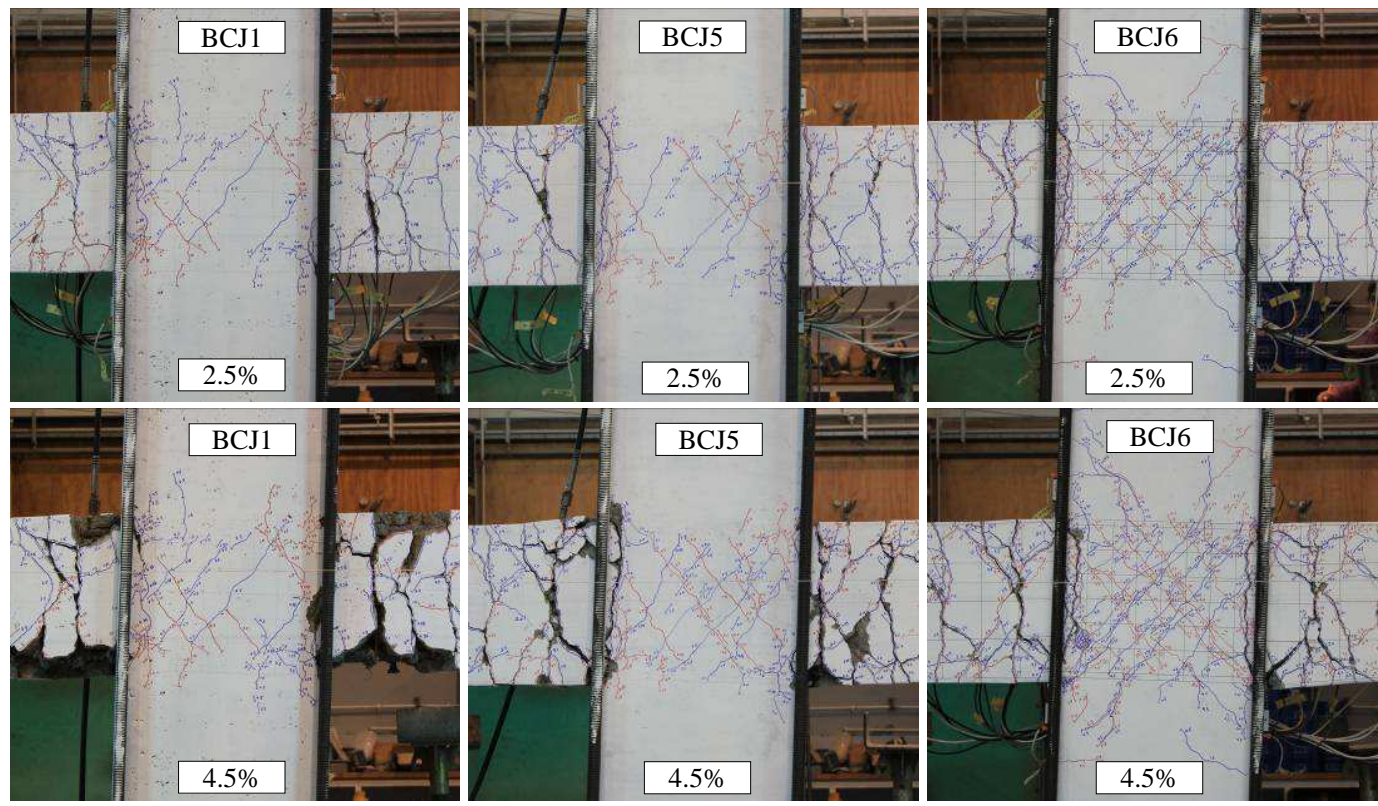

Figure 2.2.2. Pictures of BCJs at drift ratios $2.5 \%$ and $4.5 \%$

\section{RESULTS AND DISCUSSIONS}

The measured drift values were converted to equivalent ductility $(\mu)$ defined as the ratio of drift $(\delta)$ at any stage to the drift at yield $\left(\delta_{y}\right)$; this is illustrated on a secondary axis parallel to the drift axis in Fig. 2.2.1. According to the hysteresis loops (Fig. 2.2.1), for an identical ultimate drift of $4.5 \%$ BCJ1 and 
BCJ5 (HSSCC and CVHSC) proved to be more ductile than BCJ6 (CVC). This contradicts with the general notation that high-strength concrete (HSC) behaves in a brittle manner; in fact the better bond between concrete and reinforcement resulted in higher strain compatibility between the two materials; thus a higher ductility was observed. With a closer look at Fig. 2.2.1, it can be seen that the BCJ5 hysteresis loop (CVHSC, Fig. 2.2.1.b) has the smallest pinching effect amongst others. In other words it is expected that the dissipated energy in BCJ5 is more; this will later be more closely looked at when comparing the equivalent viscous damping of different specimens.

The concept of energy dissipation was used to calculate the equivalent viscous damping for all specimens (Eqn. 3.1 to 3.3). This calculation was performed in order to provide a better understanding of the hysteresis and pinching behaviours. In addition, the peak-to-peak secant stiffness degradation was also calculated (Eqn. 3.4) for all specimens. Results of damping and stiffness degradation are shown in Fig. 3.1.

$$
\begin{aligned}
& \xi_{\text {eq }}=\mathrm{E}_{\mathrm{D}} /\left(4 \pi \cdot \mathrm{E}_{\mathrm{sto}}\right) \\
& \mathrm{E}_{\mathrm{D}}=\Sigma\left(\Delta_{\mathrm{i}+1}-\Delta_{\mathrm{i}}\right)\left(\mathrm{F}_{\mathrm{i}}+\mathrm{F}_{\mathrm{i}+1}\right) / 2 \\
& \mathrm{E}_{\mathrm{sto}}=\mathrm{F}_{0} \Delta_{0} / 2 \\
& \mathrm{k}_{\mathrm{p}}=\left(\mathrm{F}_{+\mathrm{ve}}-\mathrm{F}_{\text {-ve }}\right) /\left(\Delta_{+\mathrm{ve}}-\Delta_{\text {-ve }}\right)
\end{aligned}
$$

In the above equations, ' $\xi_{\mathrm{eq}}$ ' is the equivalent viscous damping, ' $\mathrm{E}_{\mathrm{D}}$ ' is the dissipated energy per cycle (N.mm), ' $\mathrm{E}_{\text {sto }}$ ' is the equivalent elastic stored energy per cycle (N.mm), ' $F_{i}$ ' is the load at each step $(\mathrm{N}),{ }^{\prime} \Delta_{\mathrm{i}}$ ' is the displacement at each step $(\mathrm{mm}),{ }^{\prime} \mathrm{F}_{0}$ ' is the peak load of each cycle $(\mathrm{N}),{ }^{\prime} \Delta_{0}$ ' is the peak displacement of each cycle $(\mathrm{mm})$, ' $\mathrm{k}_{\mathrm{p}}$ ' is the peak-to-peak stiffness $(\mathrm{N} / \mathrm{mm})$, ' $\mathrm{F}_{+\mathrm{ve}}$ ' and ' $\mathrm{F}_{\text {-ve' }}$ ' are the maximum and minimum forces of the intended cycle $(\mathrm{N})$ and ' $\Delta_{+\mathrm{ve}}$ ' and ' $\Delta_{\mathrm{ve}}$ ' are the maximum and minimum displacements of the intended cycle $(\mathrm{mm})$.
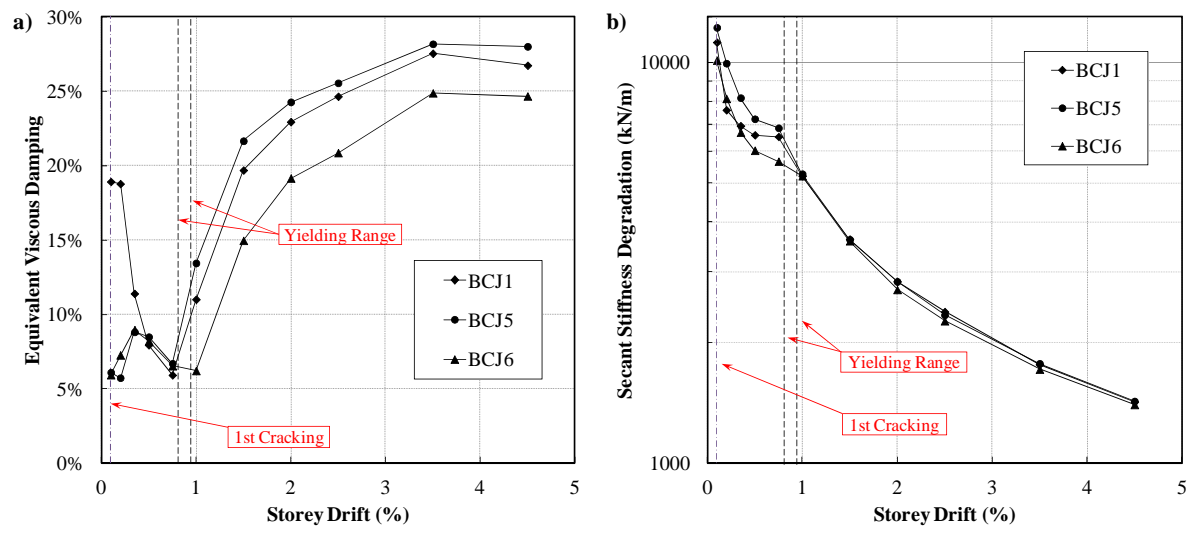

Figure 3.1. a) Equivalent viscous damping and b) Peak-to-peak secant stiffness degradation

According to Fig. 3.1 and based on the previous observations (Fig. 2.2.1) at a given drift ratio after yielding, BCJ6 shows a lower equivalent viscous damping compared to BCJ1 and BCJ5; this means that the amount of energy dissipated by the former was smaller. Before yielding, BCJ1 shows considerably higher damping compared to the others; however these initially high values decrease quite fast so that the damping values become almost the same for all specimens around the yielding point. Note that the calculation of equivalent viscous damping requires division by the elastic stored energy ' $\mathrm{E}_{\text {sto }}$ ', which is very small in the elastic response range; hence the calculated pre-yield damping values cannot be relied upon as they are very sensitive even to small discrepancies in estimating $\mathrm{E}_{\text {sto. }}$. In Fig. 3.1.b, BCJ6 shows a slightly more stiffness degradation compared to BCJ1 and BCJ5 in the pre-yield range; however after the yielding point the stiffness of all specimens tend to degrade with similar rates. 
The total joint shear force ' $V_{\mathrm{jh}}$ ' and the horizontal joint shear stress ' $\mathrm{v}_{\mathrm{jh}}$ ' at each drift peak were calculated using the geometry of the test setup and specimens. The contribution of the joint shear reinforcement to the total joint shear stress was calculated using the results of the strain gauges installed on the joint stirrups (Fig 3.2). According to the strain gauge readings, even at the highest storey drift of $4.5 \%$ none of the joint stirrups yielded; in fact they all remained elastic around halfyield levels. Therefore stresses were calculated using Hooke's law and the corresponding forces were determined by multiplying the stresses and the area of stirrups. Shear stress of the joint was also normalized with respect to the square root of concrete compressive strength ' $\mathrm{f}_{\mathrm{f}}$ ' ' to provide an unbiased assessment of the steel and concrete contributions to the total joint shear stress (Fig. 3.3).

Despite the joint shear stress being similar in the three specimens, the concrete contribution to joint shear is less in BCJ6 compared to that in BCJ1 and BCJ5. This can be attributed to the lower concrete compressive strength of the former $(48.4 \mathrm{MPa})$ which in turn results in a lesser concrete strut capacity in carrying the shear force. In addition, the concrete tensile strength is also considerably lower in BCJ6 (4.7 MPa) compared to BCJ1 and BCJ5 (7.0 and 6.5 MPa, respectively); which means that the joint stirrups should start taking their share of the shear force/stress at lower drift ratios (Fig. 3.3). The maximum limit of joint shear stress for all specimens, calculated as per the American and New Zealand standards (ACI318M-08, 2008, NZS3101, 2006) are also shown in Fig. 3.2 for comparison. As mentioned before all specimens were designed to the New Zealand Standard (NZS3101, 2006), therefore it was expected that the maximum joint shear stress would not exceed the limits.
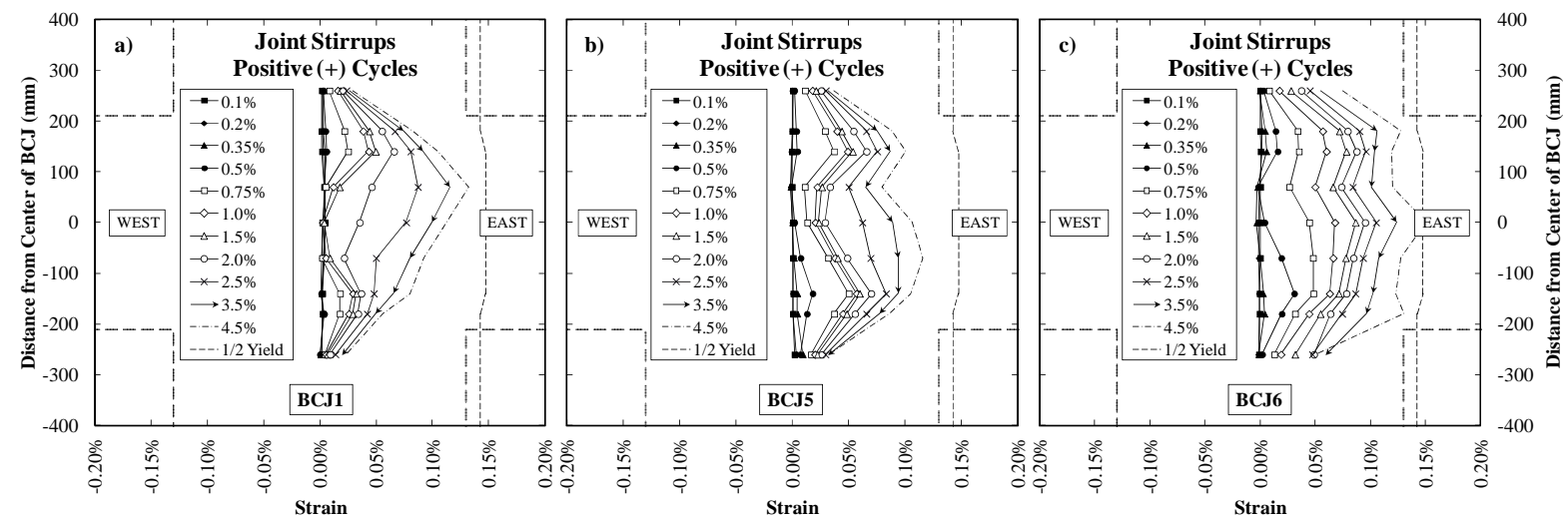

Figure 3.2. Strain profile of the joint shear reinforcement at different drift levels
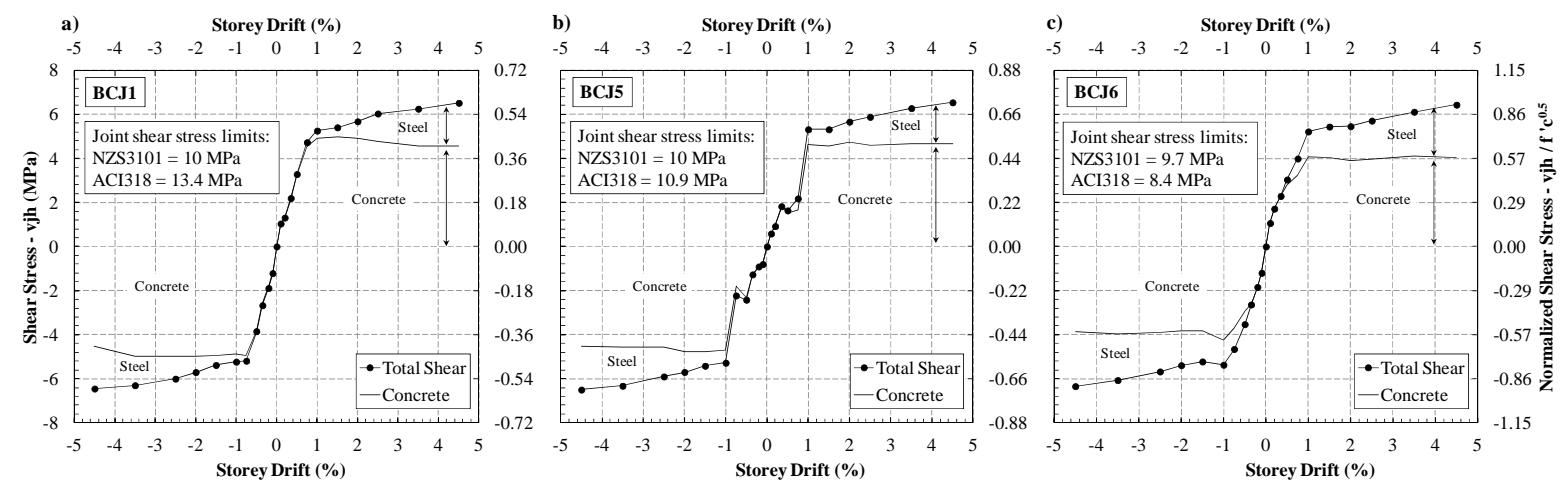

Figure 3.3. Contribution of concrete and steel in joint shear capacity

The overall deformation of a beam-column subassembly comprises of beam, column and joint deformations. As the specimens were designed to fail by the formation of plastic hinge in the beam region, the beam deformation will be contributed by four different components: elastic flexure, fixedend rotation, plastic hinge rotation and shear deformations. On the contrary, as the column was 
designed to remain elastic throughout the test, the column deformation comprises only of the elastic flexure and shear deformations. It should be mentioned that the beam and column shear deformations were considerably small compared to the other components; hence they were neglected. Finally, the joint contribution to the overall deformation comes solely from the shear deformation of the joint panel. Fig. 3.4 shows the contributions of the different elements (beam, column and joint) to the overall displacement of each specimen at the peak drifts. As could be expected based on the designed failure mode (beam hinging), the beam contributed considerably more towards the overall specimen drift than the column and the joint did. The contributions of the column and joint were almost identical in BCJ1 and BCJ5. However the joint shear deformation and its contribution to the overall drift was clearly higher in BCJ6 which had the least concrete compressive strength (48.4 MPa).
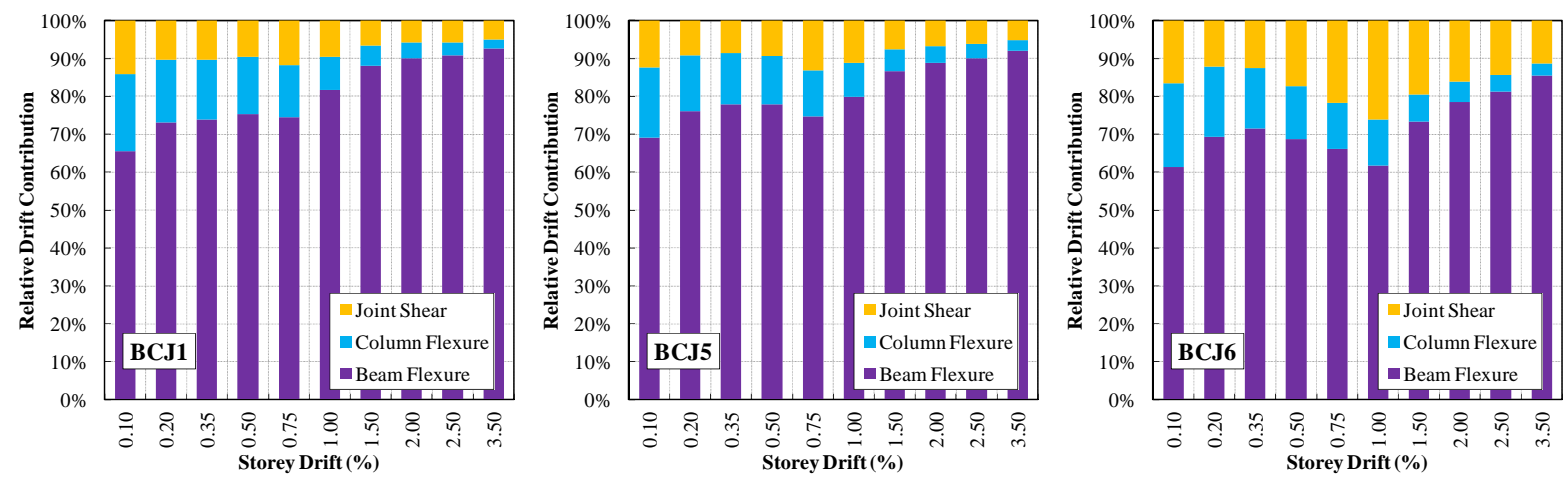

Figure 3.4. Relative contribution of different components towards the overall specimen drift

Using the LVDTs installed on the surface of specimens, the elongation of the plastic hinge zone was also calculated for the west and east beams. Total elongation (sum of the west and east) of each specimen is shown in Fig. 3.5. A closer look at the elongation graphs reveals that before yielding (at $0.75 \%$ drift for BCJ1 and BCJ5 and 1.0\% drift for BCJ6) the elongation was very small and reversible to zero for all specimens. However, it started to increase and become irreversible in nature at higher drifts (after yielding). This can be explained by the fact that when the specimens were in their elastic response region, the cracks were small and closed completely during unloading; consequently the elongations were small and reversible. However when the cracks started to widen in the larger drift cycles, small pieces of concrete dropped into the void created by the cracks. In the reverse cycle, these concrete parts started transferring the forces from one side of the crack to the other before these cracks closed completely. As a result, the reinforcement in the tension side started elongating before the cracks on the compression side fully closed down. This caused the cracks to open up in the next cycle even more and the procedure continues resulting in permanent elongation of the plastic hinge zone.
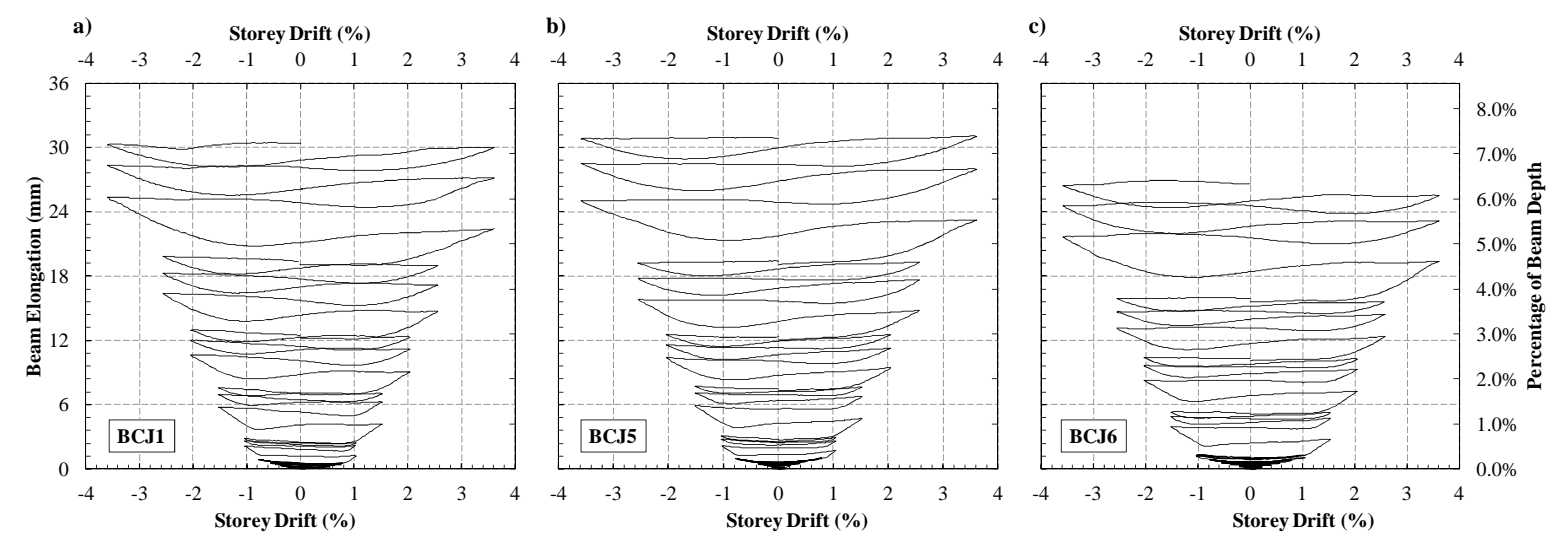

Figure 3.5. Total elongation of the plastic hinge zone (west and east beam)

It is clear from the figure that the elongation of BCJ6 was lower than that of BCJ1 and BCJ5. This can 
also be attributed to the different strength of the deteriorated concrete pieces fallen between the cracks. In BCJ6, during the crack closure the trapped concrete pieces crushed more easily (because of its lower compressive strength) compared to those in BCJ1 and BCJ5. Therefore, the resulting elongation in the reinforcing bars in the tension side of the section is less in each drift cycle for $\mathrm{BCJ} 6$ compared to that of BCJ1 and BCJ5.

\section{CONCLUSIONS}

Based on the results of this study following conclusions are drawn:

- The hysteresis loops for high-strength concrete (HSC) specimens had considerably lower pinching than that of the normal strength conventionally vibrated concrete (CVC) specimen. The hysteresis behaviour of high-strength self-compacting concrete (HSSCC) specimen showed more pinching compared to that of conventionally vibrated high-strength concrete (CVHSC) specimen.

- At a given drift ratio, significantly more cracks had appeared in the joint area of the CVC specimen compared to the other two. HSSCC had slightly less cracks in its joint area compared to the CVHSC specimen. Higher compressive strength of the HSSCC and stronger bond were the main reasons for this.

- Both HSC specimens showed a more ductile behaviour than the normal strength CVC specimen. This can be attributed to the better strain compatibility between HSC and reinforcing steel compared to that of normal strength CVC.

- Equivalent viscous damping was calculated from the hysteretic energy dissipation for all three specimens. As indicated by the pinched hysteretic loops, CVC specimen showed considerably lower damping compared to the HSC specimens.

- The peak-to-peak secant stiffness degradation was calculated for all three specimens. The stiffness of the CVC specimen degraded slightly more compared to the HSC ones before yielding. However the rate of stiffness degradation was almost the same for all specimens after yielding.

- The contribution of joint shear reinforcement and concrete in the joint shear stress were calculated for all specimens. Except for slight variations, this relative contribution was similar in the HSSCC and CVHSC specimens. However, the activation of joint stirrups was more in CVC specimen; which resulted from lower capacity of the concrete strut in carrying the shear force at a given drift. As expected, the maximum shear stress in the joint remained within the allowable standard limits.

- Various components of displacement were calculated for all specimens. It was observed that the beam had contributed the most towards the specimen overall drift in all three specimens; the contribution of column and joint were very small compared to that of the beam. In the CVC specimen the joint contribution was clearly more than that of the HSC specimens.

- The beam elongation was calculated for all specimens and it was observed that the two HSC specimens had elongated more than $7 \%$ of the beam depth compared to about $6 \%$ for the CVC specimen.

- Overall, seismic behaviour of the HSSCC and CVHSC specimens were quite similar and none of the key parameters related to seismic performance were compromised by using HSSCC. Hence, HSSCC may offer an easier option for heavily congested areas like beam-column connections in RC frame structures.

As mentioned previously, the amount of research on the seismic performance of SCC is very limited in the accessible literature and there is no information available on the cyclic behaviour of HSSCC under earthquake type excitations. It should be noted that the findings and recommendations of this study were based on a limited number of laboratory experiments conducted on HSSCC, CHVSC and $\mathrm{CVC}$ beam-column joint subassemblies. Therefore, any further generalization of these results without stronger backing from more data is not encouraged. As the concept of SCC is relatively new in the field of structural engineering, more investigations are required in order to fully understand the 
complexities involved in the seismic performance of structural members cast with this special concrete type.

\section{ACKNOWLEDGEMENT}

The authors would like to extend their sincere thanks to Tim Perigo, technician of the structures laboratory at the University of Canterbury, for his continuous support throughout the experimental stage of this study. Without his diligent efforts and high-quality inputs, fabrication and testing of the beam-column subassemblies would have become a much more tedious task. Thanks are also due to Joe Byrne, ME student at the University of Canterbury, for his cooperation in fabricating the specimens.

\section{REFERENCES}

ACI318M-08 (2008). Building code requirements for structural concrete and commentary. ACI Committee 318, 479.

ACI374.1-05 (2005). Acceptance criteria for moment frames based on structural testing and commentary. ACI Committee 374, 9.

De Almeida Filho, F.M., El Debs, M.K. and El Debs, A.L.H.C. (2008). Bond-slip behavior of self-compacting concrete and vibrated concrete using pull-out and beam tests. Materials and Structures/Materiaux et Constructions. 41:6, 1073-1089.

Desnerck, P., De Schutter, G. and Taerwe, L. (2010). Bond behaviour of reinforcing bars in self-compacting concrete: Experimental determination by using beam tests. Materials and Structures/Materiaux et Constructions. 43, 53-62.

Domone, P.L. (2006). Self-compacting concrete: An analysis of 11 years of case studies. Cement and Concrete Composites. 28:2, 197-208.

Hassan, A.A.A., Hossain, K.M.A. and Lachemi, M. (2008). Behavior of full-scale self-consolidating concrete beams in shear. Cement and Concrete Composites. 30:7, 588-96.

Lachemi, M., Hossain, K.M.A. and Lambros, V. (2005). Shear resistance of self-consolidating concrete beams experimental investigations. Canadian Journal of Civil Engineering. 32:6, 1103-1113.

NZS3101 (2006). Concrete structures standard parts $1 \& 2$ : The desing of concrete structures and commentary. Wellington, New Zealand. Standards New Zealand, 698.

Persson, B. (2001). A comparison between mechanical properties of self-compacting concrete and the corresponding properties of normal concrete. Cement and Concrete Research. 31, 193-198.

Said, A. and Nehdi, M. (2007). Behaviour of reinforced self-consolidating concrete frames. Proceedings of the Institution of Civil Engineers: Structures and Buildings. 160:2, 95-104.

Soleymani Ashtiani, M., Dhakal, R.P. and Scott, A.N. (2011). Bond properties of reinforcement in high-strength self-compacting concrete. Proceedings of the 9th Symposium on High Performance Concrete Design, Verification and Utilization. Rotorua, New Zealand.

Soleymani Ashtiani, M., Scott, A.N. and Dhakal, R.P. (2010). Mechanical properties of high-strength selfcompacting concrete. Proceedings of the 21st Australasian Conference on the Mechanics of Structures and Materials. Melbourne, Australia. 827-832.

Sonebi, M., Tamimi, A.K. and Bartos, P.J.M. (2003). Performance and cracking behavior of reinforced beams cast with self-consolidating concrete. ACI Materials Journal. 100:6, 492-500.

Valcuende, M. and Parra, C. (2009). Bond behaviour of reinforcement in self-compacting concretes. Construction and Building Materials. 23:1, 162-170. 